\title{
Numerical Analysis of the Influence of the Modification of the Ladle Shroud on Fluid Flow Behavior in a One-strand Tundish during Continuous Steel Casting
}

\author{
Hanna Suchan* ${ }_{\mathbb{C}}$, Adam Cwudziński $_{\mathbb{C}}$ \\ Czestochowa University of Technology, Faculty of Production Engineering and Materials Technology, \\ Armii Krajowej 19 ave, 42-200 Czestochowa, Poland \\ *e-mail: hanna.suchan@pcz.pl
}

(C) 2021 Authors. This is an open access publication, which can be used, distributed and reproduced in any medium according to the Creative Commons CC-BY 4.0 License requiring that the original work has been properly cited.

Received: 15 June 2021/Accepted: 16 October 2021/Published online: 10 November 2021.

This article is published with open access at AGH University of Science and Technology Journals.

\begin{abstract}
A tundish is a device from which liquid steel is pour into a mold. Therefore tundish hydrodynamic conditions have a significant impact on solidification during continuous steel casting (CSC) process. Modification of ladle shroud workspace, allows for the modification of liquid steel movement in the tundish. In the following work, numerical simulations were performed which allowed the impact of the modification of the ladle shroud workspace on the liquid steel flow structure in a one-strand tundish to be determined. In order to assess the impact of the modification of the ladle shroud on the behavior of the liquid steel in the tundish, simulations were performed, on the basis of which the percentage share of stagnant, ideal mixing and plug flow zones were determined. In addition, the mixing parameters were determined, allowing the estimation of casting duration during sequential casting. The flow fields of liquid steel for each modification of the ladle shroud were performed. The average velocity of liquid steel flowing through the tundish, the Reynolds number and turbulent intensity were also described. The obtained results showed, among others, that the application of three cylinders with a diameter of $0.041 \mathrm{~m}$ into the ladle shroud with a diameter of $0.11 \mathrm{~m}$ increases the share of active flow in the tundish in relation to the tundish with Conventional Ladle Shroud. At the same time, applying a ladle shroud with a diameter of $0.11 \mathrm{~m}$ during casting is the most favorable in relation to the hydrodynamics of the tundish.
\end{abstract}

\section{Keywords:}

continuous casting, tundish, ladle shroud, numerical simulations, hydrodynamic conditions

\section{INTRODUCTION}

A tundish is one of the devices that shapes the hydrodynamics of the liquid steel flowing through a given work space, affecting the chemical homogenization of liquid steel or the content of non-metallic inclusions in continuous slabs, blooms or billets. A tundish should be characterized by flow, which is by definition a share of minimal stagnant flow and maximum plug flow and ideal mixing, enhancing the removal of non-metallic inclusions. Therefore, it is important to test different types of tundish [1-9], including those optimized by blowing the liquid steel with an inert gas [10-13] or heating it in the tundish by means of induction [14-15]. Flow control devices, such as weirs, dams [16-18] or turbulence inhibitors $[9,19]$ are most often used to modify the hydrodynamic conditions in a tundish. The use of a ladle shroud (LS) as a device for shaping the hydrodynamics of the flow, without using dams or weirs, seems a promising approach. Selected studies related to the modification of the internal space of the ladle shroud, the depth of its immersion [20] or the introduction of inert gas into it $[21,22]$ are a reference point for the search for new solutions. Trumpet [23], dissipative [24-26] or swirling [27-29] LS are recognized modifications of the internal space of the ladle shroud. This paper presents the results of numerical simulations concerning the modification of aladle shroud for a one-strand tundish.

\section{CHARACTERISTICS OF THE TEST FACILITY}

The tested object was a one-strand tundish with a nominal capacity of $30 \mathrm{t}$. It had the shape of a wedge widening towards the pouring zone. The tundish was equipped with a low $0.12 \mathrm{~m}$ dam, containing two overflow windows with dimensions of $0.14 \times 0.05 \mathrm{~m}$, placed in front of the stopper rod system. Detailed information on the tundish has been presented in a previous publication [30]. 
The studies involved a Conventional Ladle Shroud (CLS) (Fig. 1a) and a modified ladle shroud (MLS), where the end of the main pipe was equipped with 3 smaller $0.2 \mathrm{~m}$ long cylinders, separating the main liquid steel stream. The MLS cylinder's outlets (no. 1-3) are placed in the tundish asymmetrically (Fig. 1b). The internal diameter of the main pipe was $0.07 \mathrm{~m}$ for variants 1 and 3 , and $0.11 \mathrm{~m}$ for variants 2 and 4 . The flow rate of liquid steel through the tundish in each variant of the simulation was $35 \mathrm{~kg} / \mathrm{s}$. Additional parameters defining the initial conditions of the liquid steel are presented in Table 1. All of the ladle shrouds presented in the study were immersed in liquid steel to a depth of $0.1 \mathrm{~m}$.

a)

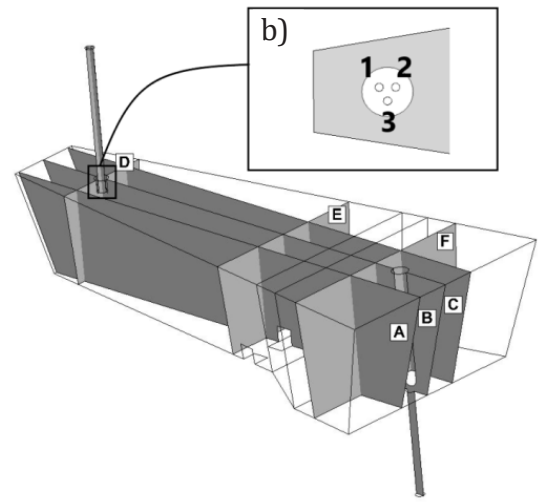

Fig. 1. One-strand slab tundish: a) analyzed planes of the tundish; b) location of the modified ladle shroud in the tundish; A-F - specific planes

The model of the tundish with ladle shrouds was made with Gambit 2.4.6 software. A computational grid consisting of an average of 855,000 tetrahedral elements was prepared using ANSYS Mesher software. Numerical simulations were performed with the help of ANSYS FLUENT 18 software.

In order to determine the hydrodynamics of the flow of liquid steel in the tundish, three planes running along the device were selected, planes A and C are areas $0.25 \mathrm{~m}$ away from the central axis of the tundish towards the side longitudinal walls.
On the other hand, the B plane goes along the mentioned axis. Three planes running across the tundish were also created: plane D, running through the center of ladle shroud, plane E was located before the low dam, and plane $\mathrm{F}$ was placed in the stopper rod zone (Fig. 1a). Circulation zones occurring on the planes A-C were indicated by rectangles.

In order to assess the impact of the modification of the ladle shroud on the behavior of the liquid steel in the tundish, simulations were performed on the basis of which the percentage share of stagnant, ideal mixing and plug flow zones were determined. Vector flow maps were also obtained. In addition, the transition zone formed during the sequential casting of two steel grades with a different chemical composition was calculated. The characteristics of individual simulation variants is presented in Table 2 .

\section{MATHEMATICAL MODEL}

The general mathematical model included the equations of continuity and momentum [30]:

$$
\begin{gathered}
\frac{\partial \rho}{\partial t}+\nabla(\rho u)=0 \\
\frac{\partial}{\partial t}(\rho u)+\nabla(\rho u u)=-\nabla p+\nabla(\overline{\bar{\tau}})+\rho g \\
\overline{\bar{\tau}}=\mu\left[\left(\nabla u+\nabla u^{T}\right)-\frac{2}{3} \nabla u I\right]
\end{gathered}
$$

where:

$$
\begin{aligned}
& t \text { - time, } \mathrm{s}, \\
& \rho \text { - density, } \mathrm{kg} \cdot \mathrm{m}^{-3}, \\
& u \text { - velocity of the steel flow, } \mathrm{m} \cdot \mathrm{s}^{-1}, \\
& g \text { - gravitational acceleration, } \mathrm{m} \cdot \mathrm{s}^{-2}, \\
& p \text { - pressure, } \mathrm{Pa}, \\
& \overline{\bar{\tau}} \text { - stress tensor, Pa, } \\
& \mu \text { - viscosity, } \mathrm{kg} \cdot \mathrm{m}^{-1} \cdot \mathrm{s}^{-1}, \\
& I \text { - unit tensor. }
\end{aligned}
$$

\begin{tabular}{|c|c|c|c|c|}
\hline $\begin{array}{l}\text { Variant } \\
\text { no. }\end{array}$ & $\begin{array}{l}\text { Liquid steel inflow at the inlet, } \\
\mathrm{m} / \mathrm{s}\end{array}$ & $\begin{array}{l}\text { Turbulence kinetic energy, } \\
\qquad \mathbf{m}^{2} / \mathbf{s}^{2}\end{array}$ & $\begin{array}{c}\text { Energy of dissipation rate of } \\
\text { kinetic energy, } \\
\mathrm{m}^{2} / \mathrm{s}^{3}\end{array}$ & $\begin{array}{l}\text { Liquid steel temperature, } \\
\qquad \mathbf{K}\end{array}$ \\
\hline 1,3 & 1.3160 & 0.017300 & 0.065140 & \multirow{2}{*}{1823} \\
\hline 2,4 & 0.5330 & 0.002840 & 0.002750 & \\
\hline
\end{tabular}

Table 1

Initial values used in the simulations

Table 2

Considered variants of the ladle shrouds- numerical simulation variants

\begin{tabular}{ccccccc}
\hline \multirow{2}{*}{$\begin{array}{c}\text { Variant } \\
\text { no. }\end{array}$} & Variant of ladle shroud & Internal diameter of the main pipe, $\mathbf{m}$ & Diameter of cylinders no. 1-3, m \\
\hline 1 & CLS & $\begin{array}{c}\text { Modified } \\
\text { ladle shroud }\end{array}$ & $\mathbf{0 . 0 7}$ & $\mathbf{0 . 1 1}$ & $\mathbf{0 . 0 2 1 8}$ & $\mathbf{0 . 0 4 1 0}$ \\
\hline 2 & $\times$ & - & $\times$ & - & - & - \\
\hline 3 & $\times$ & - & - & $\times$ & - & - \\
\hline 4 & - & $\times$ & $\times$ & $\times$ & - & $\times$ \\
\hline
\end{tabular}


The effect of the temperature gradient in the liquid steel was calculated on the basis of the energy equations [30]:

$$
\begin{gathered}
\frac{\partial}{\partial t}(\rho E)+\nabla(u(\rho E+p))=\nabla\left(k_{e f f} \nabla T-\sum h J+\left(\overline{\bar{\tau}}_{e f f} \cdot u\right)\right) \\
E=h-\frac{p}{\rho}+\frac{u^{2}}{2}
\end{gathered}
$$

where:

$$
\begin{aligned}
\overline{\bar{\tau}}_{e f f} & \text { - effective stress tensor, } \mathrm{Pa}, \\
T & \text { - temperature, } \mathrm{K}, \\
E & \text { - energy, J, } \\
h & \text { - enthalpy, J, } \\
k_{\text {eff }} & \text { - effective thermal conductivity, } \mathrm{W} \cdot \mathrm{m}^{-1} \cdot \mathrm{K}^{-1}, \\
J & \text { - diffusion flux, } \mathrm{kg} \cdot \mathrm{m}^{-2} \cdot \mathrm{s}^{-1} .
\end{aligned}
$$

Species transport equation was used to calculate tracer motion in the liquid steel within time [30]:

$$
\frac{\partial C_{i}}{\partial t}+\nabla\left(-D_{i} \nabla C_{i}+C_{i} u\right)=0
$$

Under non-isothermal conditions, a polynomial density model was applied [31]:

$$
\rho=8300-0.7105 T
$$

where:

$$
\begin{aligned}
& C_{i} \text { - concentration of the tracer, } \mathrm{kg}, \\
& D_{i}-\text { diffusion coefficient of the tracer, } \mathrm{m}^{2} \cdot \mathrm{s}^{-1} .
\end{aligned}
$$

To describe the turbulent movement of liquid steel, the realizable $k-\varepsilon$ model was adopted, which uses the following constant values: $\mathrm{C}_{2}=1.9, \sigma_{k}=1.0, \sigma_{\varepsilon}=1.2$.

In the conducted numerical simulations, the medium flowing through the tundish was liquid steel of the following parameters: viscosity $-0.007 \mathrm{~kg} /(\mathrm{m} \cdot \mathrm{s})$, thermal conductivity of steel $-41 \mathrm{~W} /(\mathrm{m} \cdot \mathrm{K})$, heat capacity of steel $-750 \mathrm{~J} /(\mathrm{kg} \cdot \mathrm{K})$. The simulation of non-isothermal conditions of the CSC process was performed, assuming thermal losses, in the form of: $-2600 \mathrm{~W} / \mathrm{m}^{2}$ for the walls and bottom of the tundish; $-15000 \mathrm{~W} / \mathrm{m}^{2}$ for the free surface of liquid steel and $-1750 \mathrm{~W} / \mathrm{m}^{2}$ for the walls of elements immersed in a liquid, i.e. a stopper rod, a dam or a ladle shroud wall [30]. Natural convection was also considered. The top wall of the tundish with assumed zero tangential stresses was assumed as a free surface. Other walls were assumed as a standard wall function. The SIMPLEC (Semi-Implicit Method for Pressure-Linked Equations-Consistent) algorithm was used to describe the coupling of the pressure and velocity fields in the model. The UDS (User Defined Scalars) function was used to simulate the marker. The numerical model presented has been validated by industrial and physical trials in the co-authors previous work [31, 32]. The registration of the marker concentration change as a function of time was the basis for the determination of RTD (Residence Time Distribution) curves. Based on previous papers [30, 33], the duration of the transition zone was determined on the basis of the F-curve in the range of dimensionless concentration within the range of 0.2-0.8. The simulations were performed with two simplifications during ladle change over: steady level of liquid steel in the tundish and steady casting speed. The intensity of turbulence in the pouring zone of the tundish on the B plane was also analyzed, and the average flow rate of the liquid steel through the tundish was determined. The Reynolds number was also calculated (8):

$$
R e=\frac{\rho L v_{a v}}{\eta}
$$

where:

$$
\begin{aligned}
& \rho \text { - density of liquid steel, } \mathrm{kg} / \mathrm{m}^{3}, \\
& L \text { - liquid steel depth in the tundish, } \mathrm{m}, \\
& v_{a v} \text { - average velocity of liquid steel in the tundish, } \mathrm{m} / \mathrm{s}, \\
& \eta \text { - viscosity of liquid steel, } \mathrm{kg} /(\mathrm{m} \cdot \mathrm{s}) .
\end{aligned}
$$

Turbulence intensity was described by means of the following Equation (9):

$$
I=\frac{\sqrt{\frac{2}{3} k}}{u}
$$

where:

$$
\begin{aligned}
& k \text { - kinetic energy, } \mathrm{m}^{2} / \mathrm{s}^{2}, \\
& u \text { - liqvelocity of the steel flow, } \mathrm{m} \cdot \mathrm{s}^{-1} \text {. }
\end{aligned}
$$

\section{RESULTS AND DISCUSSION}

While analyzing the flow of liquid steel on plane A, a circulation zone was found in each variant in the area of the tundish stopper rod system (rectangle 1 at Fig. 2a-d). The circulation is the largest in variants 3 and 4 . In each of the variants, there is also a recirculation located at the ladle shroud, under the free surface of the liquid steel, which differs in shape and size depending on the ladle shroud variant (Plane A, rectangle 4 at Fig. 2a, Fig. 2c, Fig. 2d and Plane A, rectangle 3 at Fig. 2b). A characteristic circulation (not appearing in variant 2 ) is the circulation located under the free surface of the metal, between the pouring zone and the low overflow dam (Plane A, rectangle 2 at Fig. 2a, Fig. 2c and Fig. 2d). The $\mathrm{C}$ plane shows a similar flow to the symmetrical A plane. Circulations are formed in similar places, they differ only in shape or size. The biggest difference can be observed in the case of variant 4 (Fig. 2d). The recirculation zone in the area of the tundish stopper rod system takes an angle to a little horizontal (it occurs similarly in variant 3 ) (Plane C, rectangle 1 at Fig. 2c and Fig. 2d). The sizes of the circulation areas located at the ladle shroud under the free surface of the liquid steel also change. In variants 2 and 4 (rectangle 3 at Fig. $2 \mathrm{~b}$ and rectangle 4 at Fig. 2 d), where the circulation at the ladle shroud on the A plane was smaller, it is characterized by a larger size on the $C$ plane, unlike in variants 1 and 3 (rectangle 4 at Fig. 2a and Fig. 2c), where the recirculation has a larger surface on the A plane and occupies a smaller area on the $\mathrm{C}$ plane. The B plane indicates a similar liquid steel flow through the tundish between the variants. Two circulation zones come to the fore. One is located between the pouring stream and the closer short wall of the device (rectangle 1 at Fig. 3a-d), while the other is shaped in the middle of the tundish bottom, between the above-mentioned short wall and the overflow dam (rectangle 2 at Fig. 3a-d). 
a)

Plane A

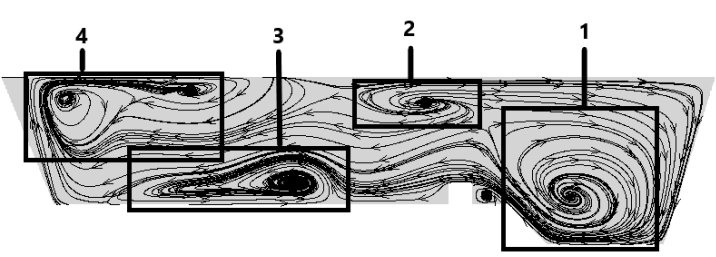

b)

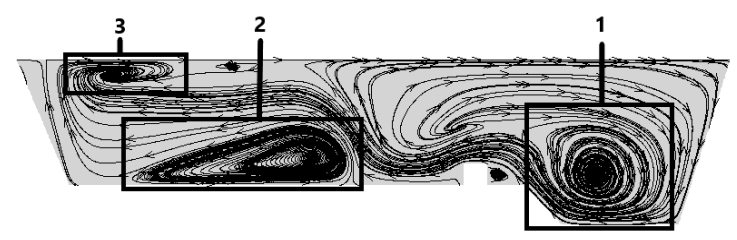

c)

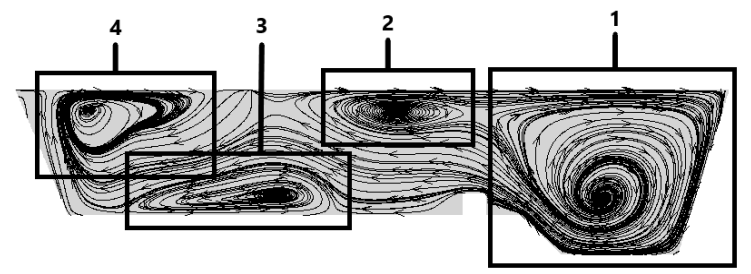

d)

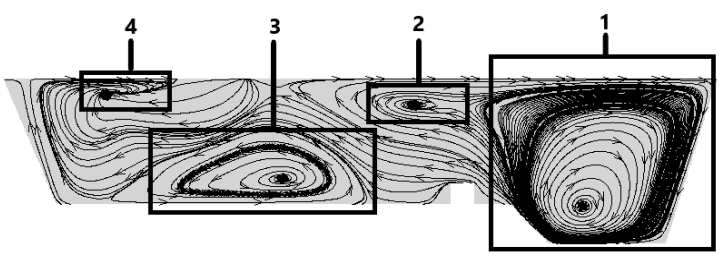

Plane C
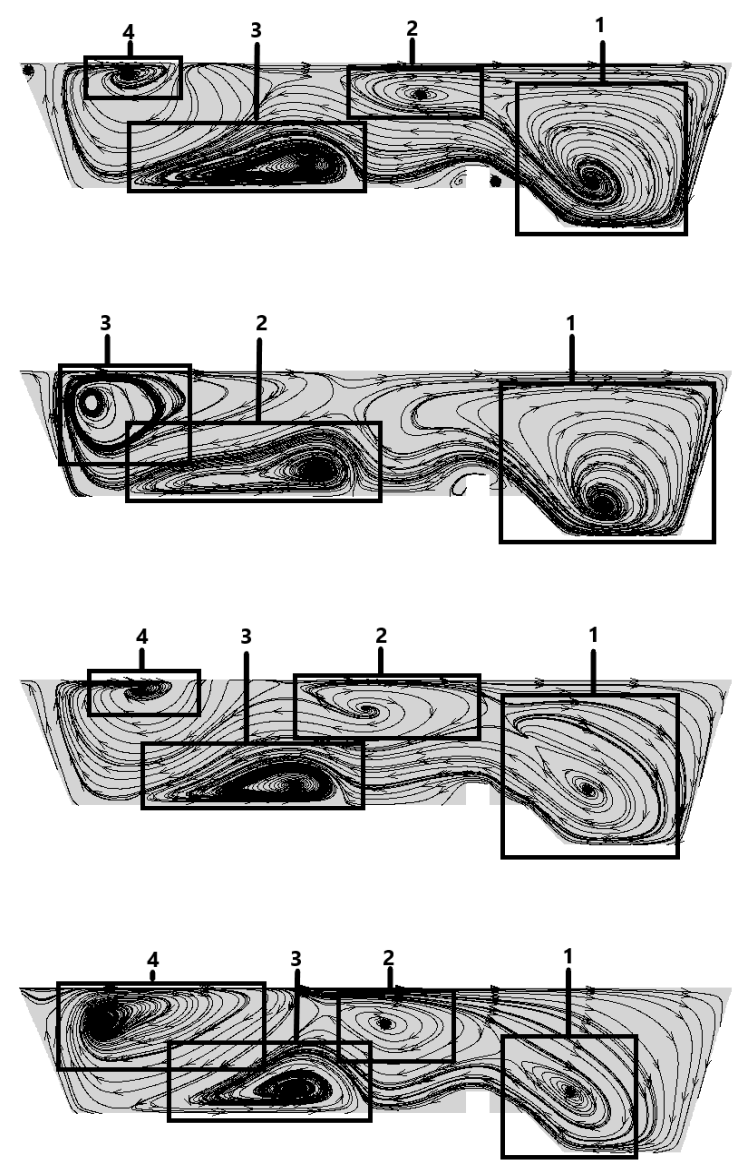

Fig. 2. Liquid steel paths for planes A and C: a) variant no. 1; b) variant no. 2; c) variant no. 3; d) variant no. 4

a)

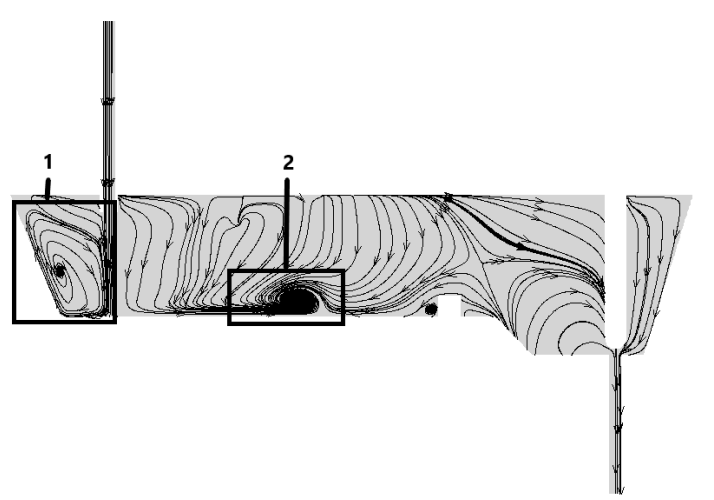

c)

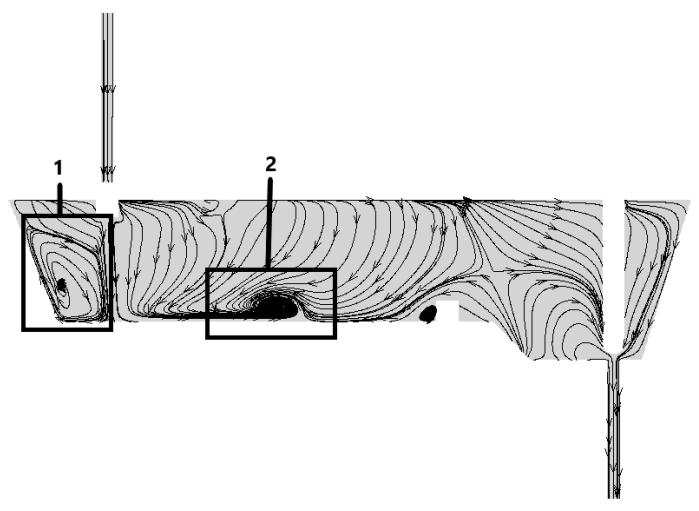

b)

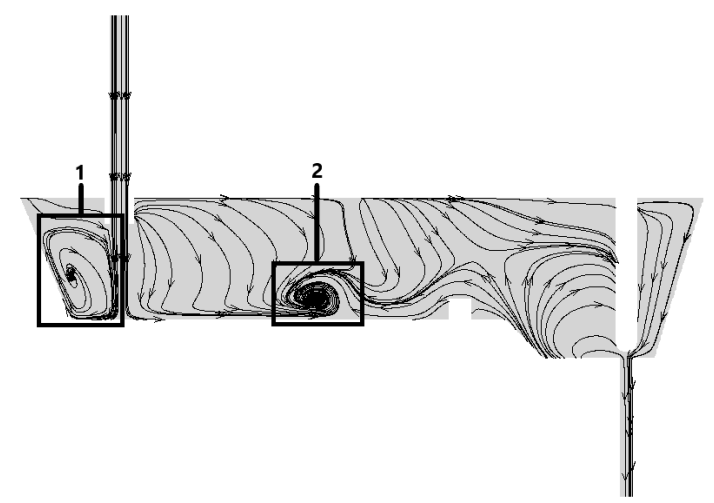

d)

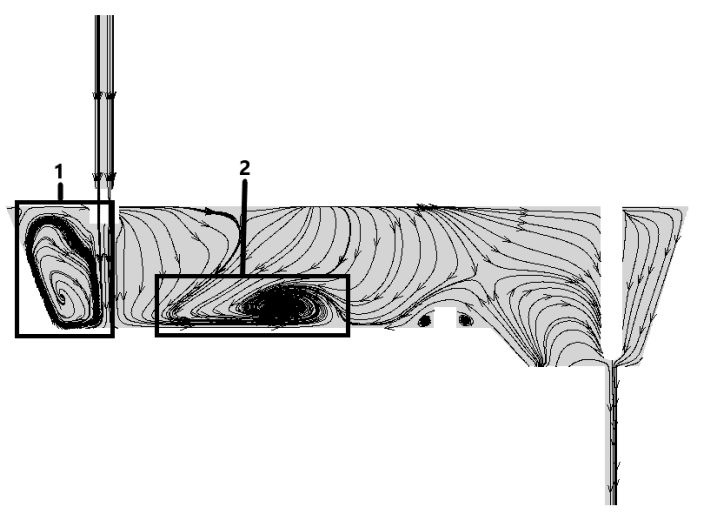

Fig. 3. Liquid steel paths for the plane B: a) variant no. 1; b) variant no. 2; c) variant no. 3; d) variant no. 4 
Analysis of velocity paths on the plane D shows circulation areas at both sides of the pouring stream, and whose sizes are very similar to each other (Plane D, Fig. 4). As the liquid steel flows through the stopper rod, circulations decrease (Plane E, Fig. 4) until they reach the stopper rod zone where they are mostly very small (the exception is variant no. 3) (Plane F, Fig. 4).
In all variants on plane $\mathrm{E}$ they are circulations under the free surface of a metal bath. In variants no. 1, 3 and 4 (Plane E, Fig.4a, Fig. 4c and Fig. 4d), very small vortices are creating at the bottom of the tundish. On plane F, fluid flow is asymmetrical in all variants. The most similar flow field at plane $\mathrm{E}$ occurs in variant no. 3 .
Plane D

a)

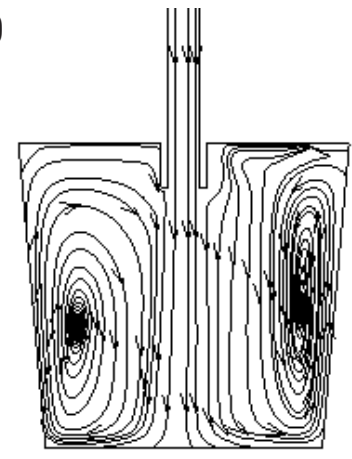

Plane E

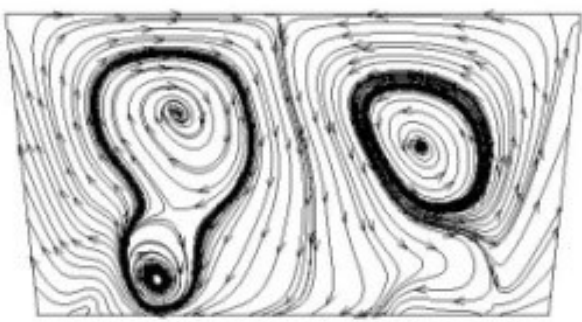

b)

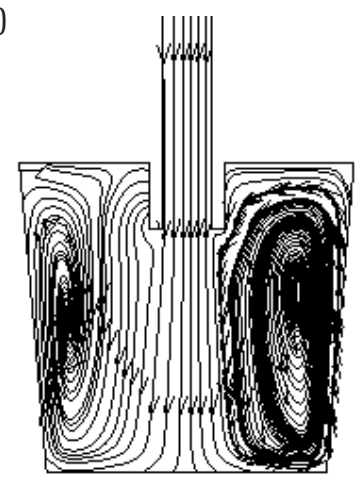

c)
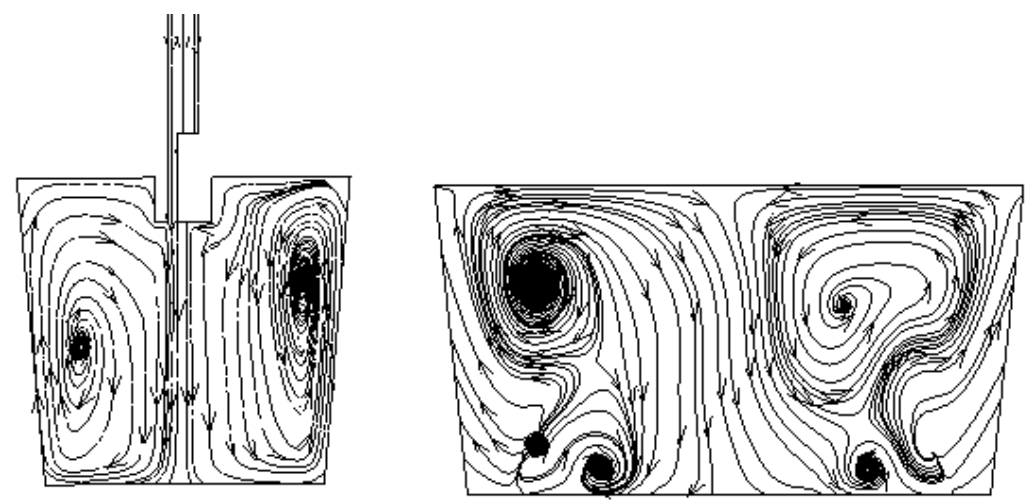
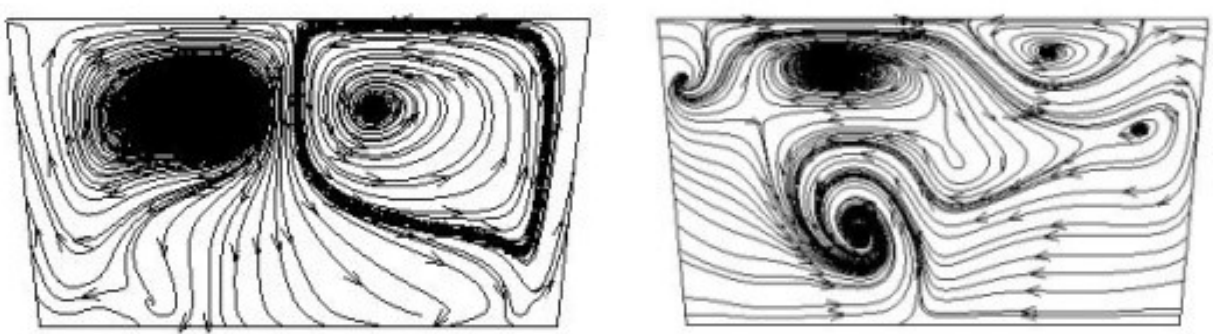

Plane F
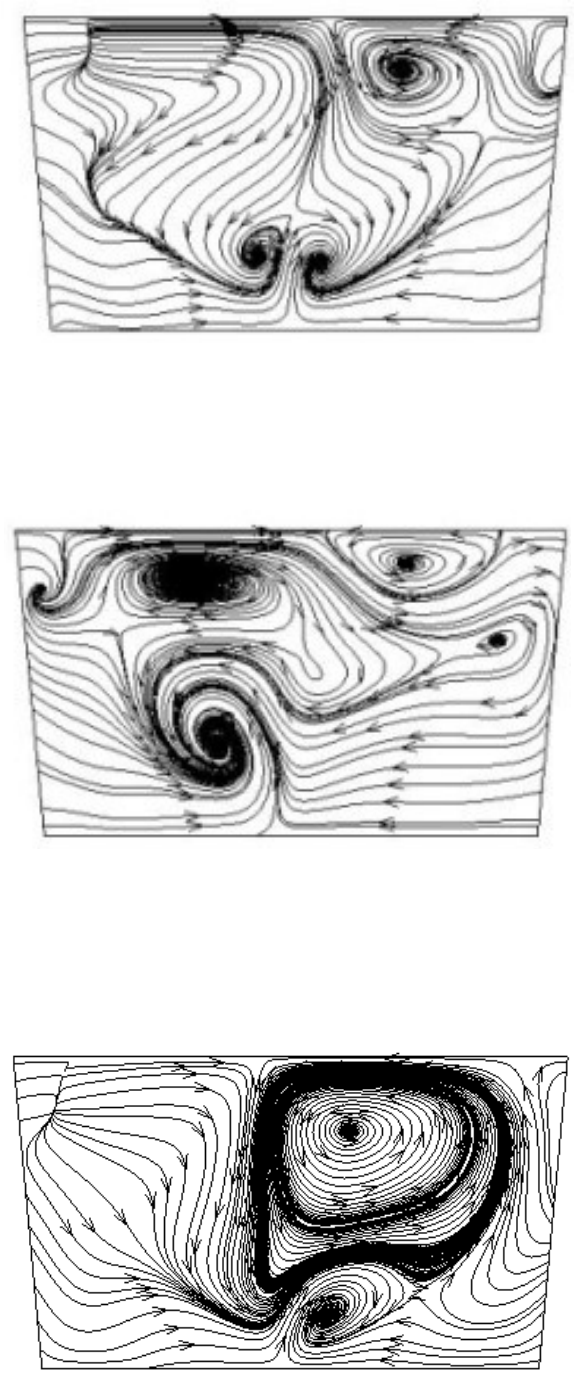

d)
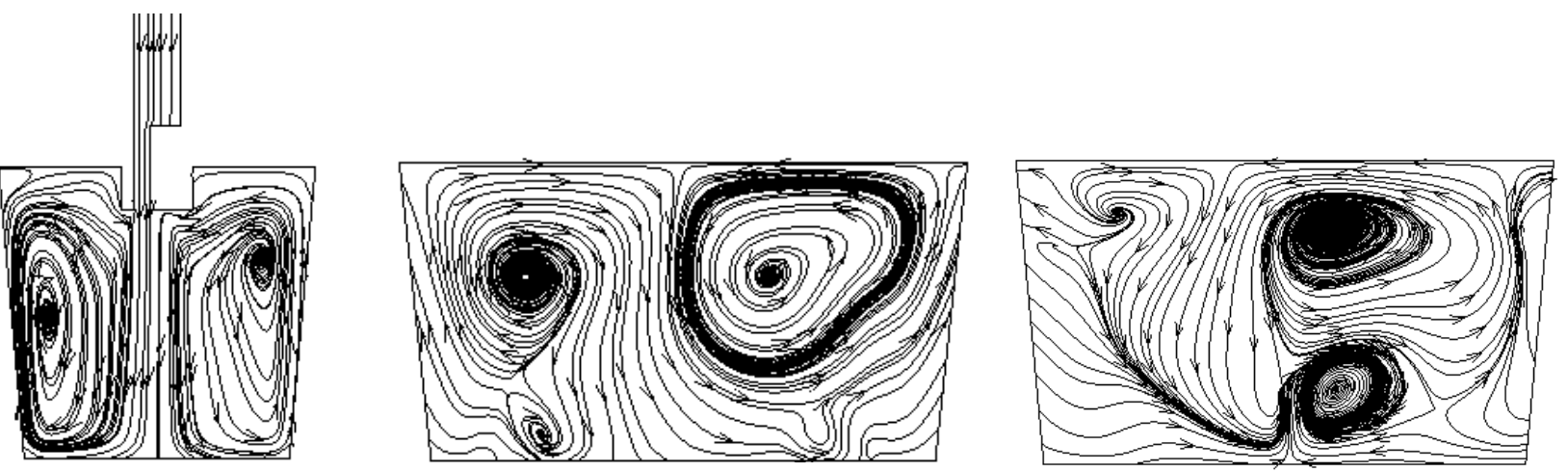

Fig. 4. Liquid steel paths at Plane D, Plane E and Plane F: a) variant no. 1; b) variant no. 2; c) variant no. 3; d) variant no. 4 
a)

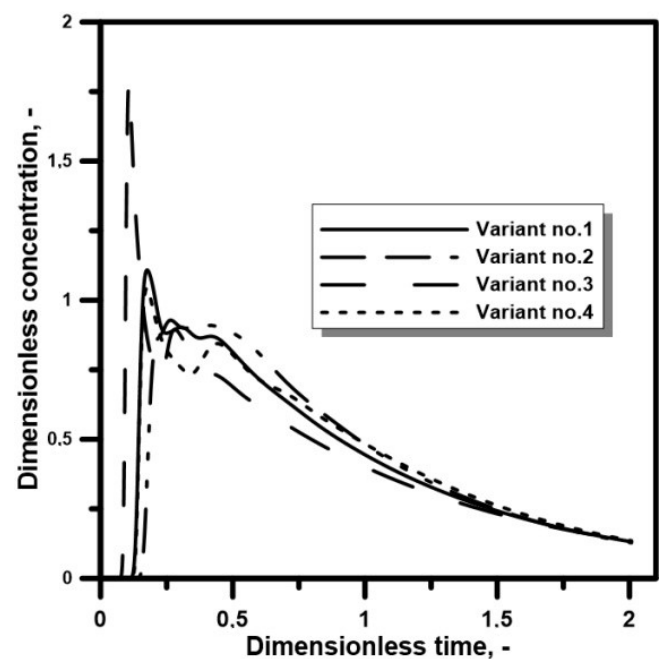

c)

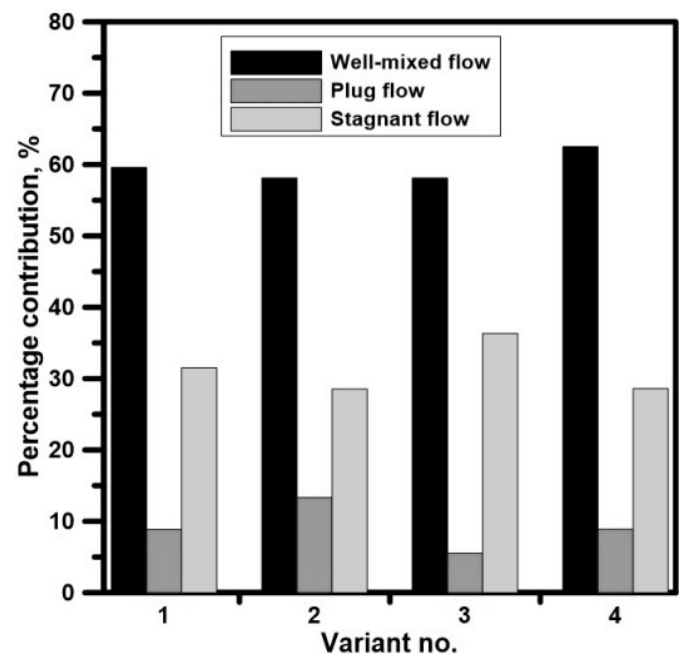

b)

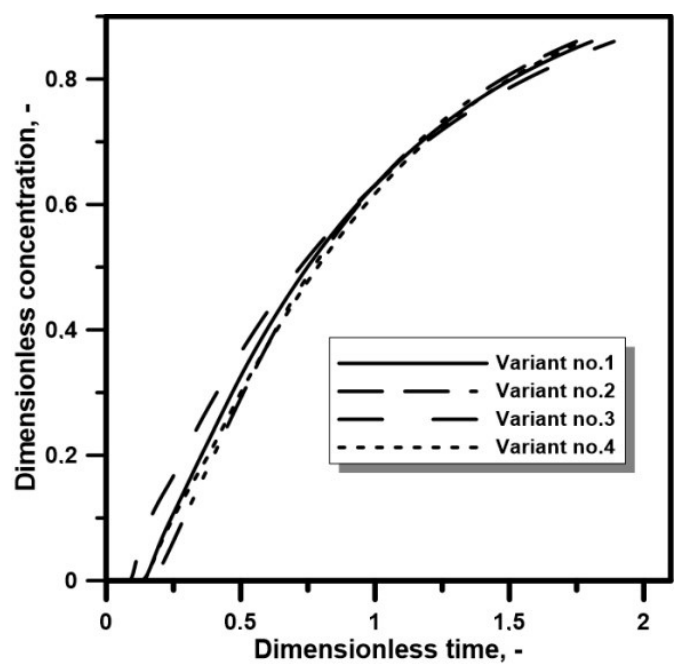

d)

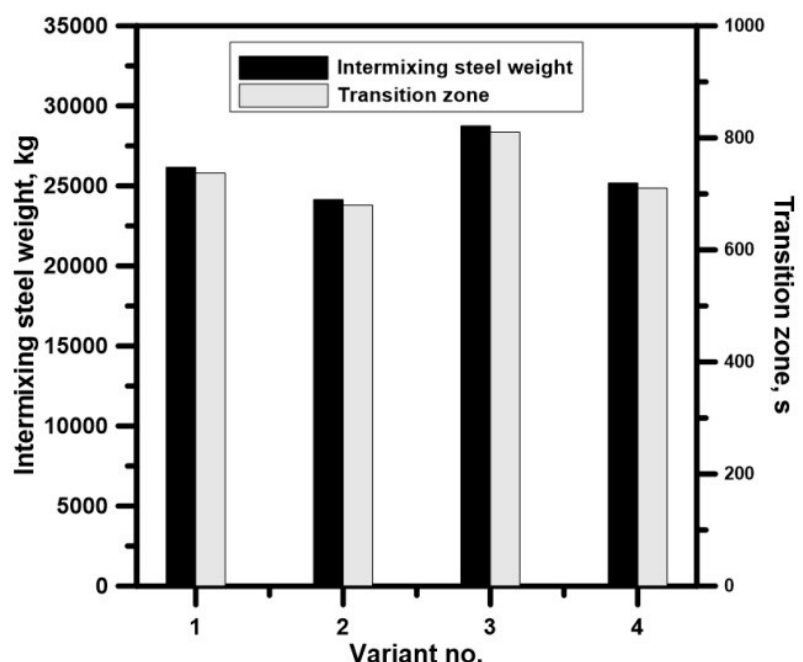

Fig. 5. Tundish hydrodynamic conditions: a) RTD curve-type E; b) RTD curve-type F; c) active and stagnant flow for the considered variants; d) transition zone in consider variants

While analyzing the percentage share of the volume of individual flows, it was observed that the highest share of active flow was found in two variants: 2 and 4, and its value was approx. $71.4 \%$. The mentioned variants differ in the share of the ideal mixing flow and the plug flow. The share of ideal mixing flow for variant 4 is $62.52 \%$, while for variant 2 it is $58.13 \%$. Variant 3 is marked by the same share of the ideal mixing flow exceeding $57 \%$ as in the case of variant 2 . At the same time, the share of the plug flow in the variant with a modified ladle shroud with a main pipe $0.07 \mathrm{~m}$ in diameter is slightly over $5 \%$. The mentioned variant unfavorably affects the results due to the high share of stagnant flow, which is over $36 \%$. Variant 1 has almost the same plug flow share as variant 4 , while the ideal mixing flow share is $59.6 \%$ (Fig. 5a and Fig. 5c). Additionally, as part of the analysis of the effect of the ladle shroud on the hydrodynamics of liquid steel flow through the tundish, the transition zone was determined. Based on the range of transition zone, casting speed, steel density and the dimensions of the slab, it was possible to calculate the approximate weight of the mixed steel grade. The lowest weight of the steel in the intermixing zone was obtained for variant $2-24146 \mathrm{~kg}$, and the highest for variant $3-28475 \mathrm{~kg}$. Comparing the obtained results with the basic ladle shroud defined as variant 1 , variant 4 also has a favorable effect, since the weight of the mixed grade obtained as a result of applying this modification is $979 \mathrm{~kg}$ lower (Fig. 5b and Fig. 5d). The highest weight of the steel in the intermixing zone in variant 3 occurs due to the highest share of stagnant flow of all variants. The lowest weight of steel in the intermixing zone in variant 2 is due to a small share of stagnant flow and the highest share of plug flow.

While analyzing the diagram showing the velocities of liquid steel for the lines passing through the individual internal cylinders of the ladle shroud (Fig. 6) in variants 3 and 4 , a significant increase in the liquid steel velocity was observed at the height of approx. 0.75-1.15 m, which corresponds to the modification located here. Liquid steel velocity expansion is a result of decreasing area of ladle shroud outflow by using cylinders. The highest liquid steel velocity was recorded for variant 3 (smaller diameter of cylinders). The diagram also presents the differences in the velocities of the liquid steel between lines 1, 2 and 3 in the vicinity of the tundish bottom. The biggest differences appear in variant 3 . 


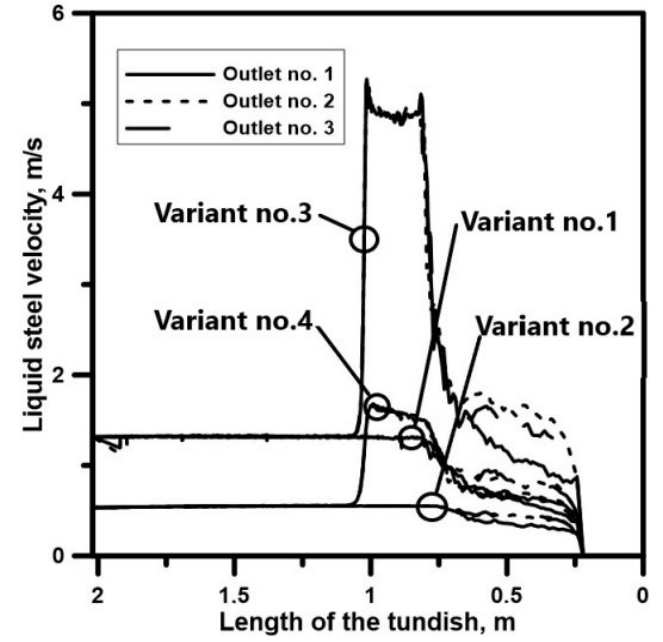

Fig. 6. Velocity magnitudes for lines passing through the distinct outlets of ladle shroud

The highest average velocity of liquid steel in the tundish (Fig. 7) of less than $0.07 \mathrm{~m} / \mathrm{s}$ was obtained in variant 3 . On the other hand, the lowest velocity occurs in variant 2 . Variants 1 and 4 are characterized by similar values of the average velocity and Reynolds number. Due to the fact that the Reynolds number depends on the velocity of the liquid steel in the tundish, similar dependencies occur in the value of the Reynolds number for variants 2 and 4 . The highest Reynolds number occurs in variant 3 , and the lowest in variant 2 .

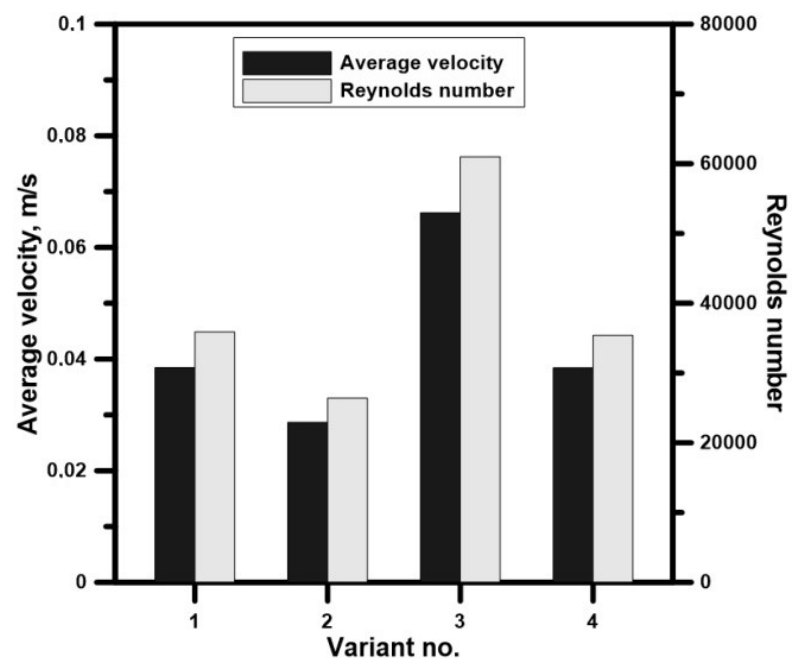

Fig. 7. Average liquid steel velocity in the tundish and Reynolds number for consider variants

The intensity of turbulence in the pouring zone on the B plane was also analyzed (Fig. 8). In variants 1 and 4, turbulences arise in the area of the flood stream and at the bottom of the tundish as a result of the contact of the liquid steel flowing into the tundish with its bottom. In variant 4 , they are slightly more intense at the ladle shroud than in variant 1 . The largest area of turbulence with increased intensity occurs in variant 3 , and the intensity of turbulence with the maximum value is located under the ladle shroud. In variant 2 , the intensity of turbulence in the analyzed range is characterized by the smallest fluctuations. a)

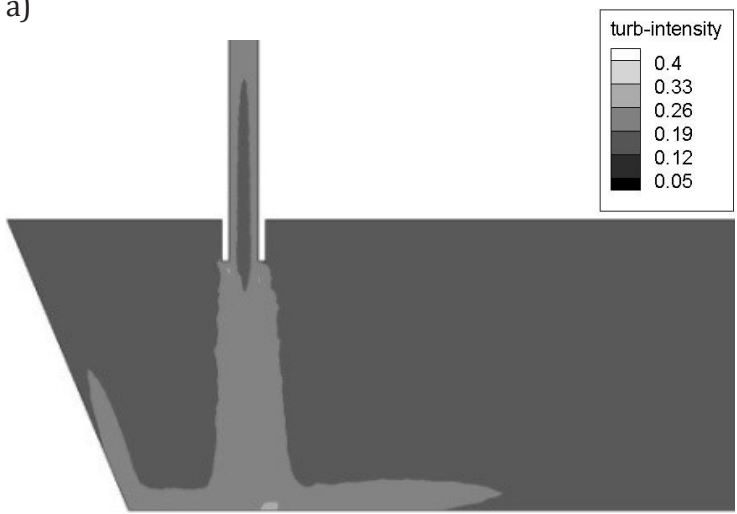

b)

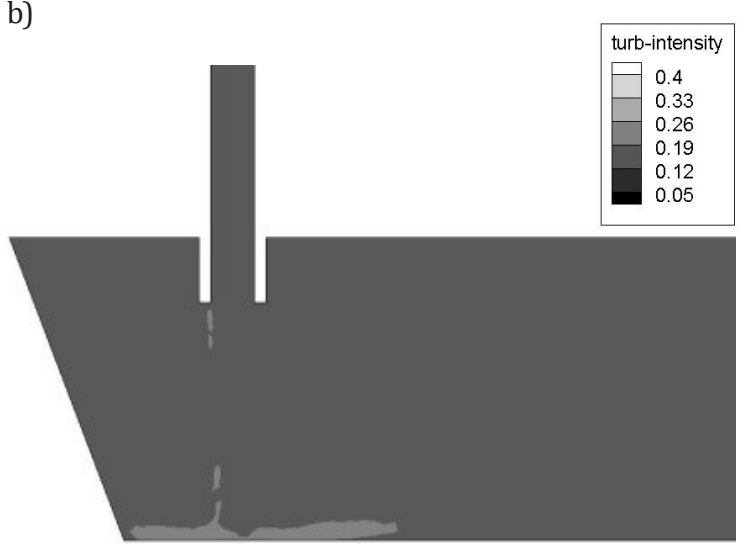

c)

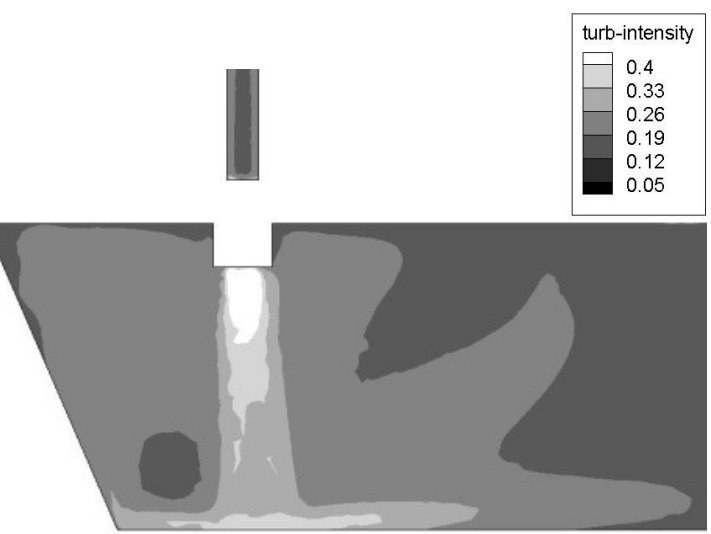

d)

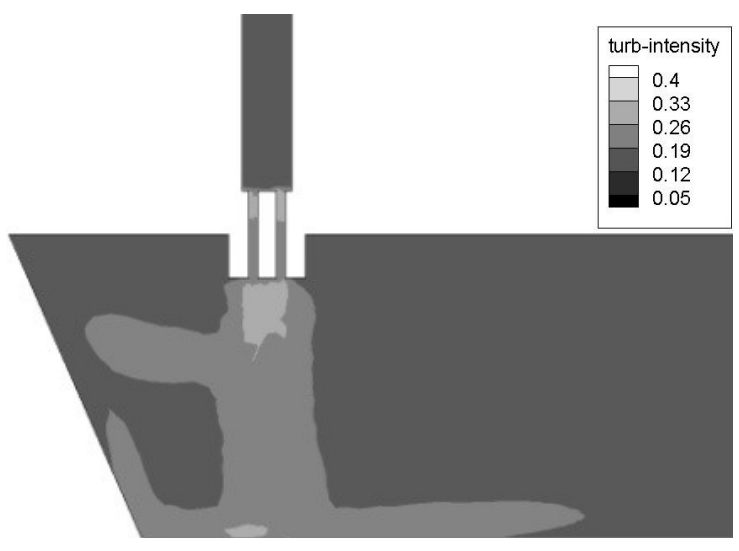

Fig. 8. Turbulence intensity maps for the plane B for the impact zone: a) variant no. 1 ; b) variant no. 2 ; c) variant no. 3 ; d) variant no. 4 


\section{CONCLUSION}

Based on the performed numerical simulations, it was found that:

- The use of the tested variants of the ladle shroud does not significantly affect the shape of the directions of liquid steel flow, but it does affect the intensity of turbulence in the pouring zone.

- Reduction in the diameter of the main pipe and reduction in the diameter of the cylinders modifying the internal space of ladle shroud increases the flow rate of liquid steel within the modification, which may intensify the erosion of the ladle shroud.

- The use of cylinders in a ladle shroud with a diameter of $0.07 \mathrm{~m}$ causes a $100 \%$ increase in the average velocity of liquid steel in the tundish, at the same time adversely modifying the hydrodynamic structure (increase in the stagnant flow share).

- The application of three cylinders with a diameter of $0.041 \mathrm{~m}$ for the ladle shroud with a $0.11 \mathrm{~m}$ diameter of main pipe increases the share of active flow in the tundish in relation to the base ladle shroud (tundish variant 1).

- Applying a ladle shroud with a diameter of $0.11 \mathrm{~m}$ during casting in the considered tundish is the most favorable in relation to the hydrodynamics of the tundish.

\section{Acknowledgments}

This research was carried out as a part of the following statutory research: $B S / P B-200-301 / 2020$ and $B S / P B-200-301 / 2021$.

\section{REFERENCES}

[1] Yang S., Zhang L., Li J. \& Peaslee K. (2009). Structure optimization of horizontal continuous casting tundishes using mathematical modeling and water modeling. Iron and Steel Institute of Japan International, 49(10), 1551-1560. Doi: https://doi.org/ 10.2355/isijinternational.49.1551.

[2] Hou Q.F. \& Zou Z.S. (2005). Numerical and physical simulation of flow patterns in a swirling flow tundish. Steel Research International, 76(10), 726-730. Doi: https://doi.org/10.1002/srin. 200506087.

[3] Ni P., Jonsson L.T.I., Ersson M. \& Jonsson P.G. (2016). A new tundish design to produce a swirling flow in the SEN during continuous casting of steel. Steel Research International, 87(10), 1356-1365. Doi: https://doi.org/10.1002/srin.201500407.

[4] Wang F., Li B. \& Tsukihashi F. (2007). Large eddy simulation on flow structure in centrifugal flow tundish. Iron and Steel Institute of Japan International, 47(4), 568-573. Doi: https://doi.org/ 10.2355/isijinternational.47.568.

[5] Tripathi A. \& Ajmani S.K. (2005). Numerical investigation of fluid flow phenomenon in a curved shape tundish of billet caster. Iron and Steel Institute of Japan International, 45(11), 1616-1625. Doi: https://doi.org/10.2355/isijinternational.45.1616.

[6] Liu S., Yang X., Du L., Li L. \& Liu C. (2008). Hydrodynamic and mathematical simulations of flow field and temperature profile in an asymmetrical T-type single-strand continuous casting tundish. Iron and Steel Institute of Japan International, 48(12), 1712-1721. Doi: https://doi.org/10.2355/isijinternational.48.1712.

[7] Hou Q., Yue Q., Wang H., Zou Z. \& Yu A. (2008). Modelling of inclusion motion and flow patterns in swirling flow tundishes with symmetrical and asymmetrical structures. Iron and Steel Institute of Japan International, 48(6), 787-792. Doi: https:// doi.org/10.2355/isijinternational.48.787.
[8] Zhong L., Li B., Zhu Y., Wang R., Wang W. \& Zhang X. (2007). Fluid flow in a four-strand bloom continuous casting tundish with different flow modifiers. Iron and Steel Institute of Japan International, 47(1), 88-94. Doi: https://doi.org/10.2355/ isijinternational.47.88.

[9] Tripathi A. \& Ajmani S.K. (2011). Effect of shape and flow control devices on the fluid flow characteristics in three different industrial six strand billet caster tundish. Iron and Steel Institute of Japan International, 51(10), 1647-1656. Doi: https:// doi.org/10.2355/isijinternational.51.1647.

[10] Wang J., Zhu M., Zhou H. \& Wang Y. (2008). Fluid flow and interfacial phenomenon of slag and metal in continuous casting tundish with argon blowing. Journal of Iron and Steel Research, International, 15(4), 26-31. Doi:https://doi.org/10.1016/S1006$-706 \times(08) 60139-9$.

[11] Zhong L., Li L., Wang B., Jiang M., Zhu L., Zhang L. \& Chen R. (2006). Water modelling experiments of argon bubbling curtain in a slab continuous casting tundish. Steel Research International, 77(2), 103-106. Doi: https://doi.org/10.1002/srin. 200606361.

[12] Holzinger G. \& Thumfart M. (2019). Flow interaction in continuous casting tundish due to bubble curtain operations. Steel Research International, 90(6). Doi: https://doi.org/10.1002/srin. 201800642

[13] Thumfart M., Pelss A. \& Pfeifer H. (2019). Experimental investigation of the influence of a centered line sparger on the jet from the shroud in a 1:3 water model of a tundish. Steel Research International, 90(6). Doi: https://doi.org/10.1002/srin. 201800639.

[14] Xing F., Zheng S. \& Zhu M. (2018). Motion and removal of inclusions in new induction heating tundish. Steel Research International, 89(6). Doi: https://doi.org/10.1002/srin.201700542.

[15] Yang B., Lei H., Bi Q., Jiang J., Zhang H., Zhao Y. \& Zhou J.A. (2018). Fluid flow and heat transfer in a tundish with channel type induction heating. Steel Research International, 89(10). Doi: https://doi.org/10.1002/srin.201800173.

[16] Wang G., Yun M., Zhang C. \& Xiao G. (2015). Flow mechanism of molten steel in a single-strand slab caster tundish based on the Residence Time Distribution curve and data. Iron and Steel Institute of Japan International, 55(5), 984-992. Doi: https://doi. org/10.2355/isijinternational.55.984.

[17] Jha P.K., Rao P.S. \& Dewan A. (2008). Effect of height and position of dams on inclusion removal in a six strand tundish. Iron and Steel Institute of Japan International, 48(2), 154-160. Doi: https://doi.org/10.2355/isijinternational.48.154.

[18] He F., Zhang L. \& Xu Q. (2016). Optimization of flow control devices for a T-type five-strand billet caster tundish: water modeling and numerical simulation. China Foundry, 13(30), 166-175. Doi: https://doi.org/10.1007/s41230-016-5132-9.

[19] Delgado Ramirez O.S., Torres Alonso E., Ramos Banderas J.A., Arreola Villa S.A., Hernandez Bacanegra C.A. \& Tellez Martinez J.S. (2018). Thermal and fluid-dynamic optimization of a five strand asymmetric delta shaped billet caster tundish. Steel Research International, 89(3), 1700428. Doi: https://doi.org/10.1002/ srin.201700428.

[20] Bartosiewicz M. \& Cwudziński A. (2017). Influence of immersion depth of ladle shroud in liquid steel on range of transition zone for one-strand tundish during continuous casting of steel. Metallurgy and Foundry Engineering, 43(2), 81-88. Doi: https:// doi.org/10.7494/mafe.2017.43.2.81.

[21] Chatterjee S. \& Chattopadhyay K. (2016). Physical modeling of slag 'eye' in an inert gas-shrouded tundish using dimensional analysis. Metallurgical and Materials Transactions B, 47, 508-521. Doi: https://doi.org/10.1007/s11663-015-0512-x.

[22] Chattopadhyay K., Hasan M., Isac M. \& Guthrie R.I.L. (2010). Physical and mathematical modeling of inert gas-shrouded ladle nozzles and their role on slag behavior in fluid flow patterns in a delta-shaped, four-strand tundish. Metallurgical and Materials Transaction B, 41, 225-233. Doi: https://doi.org/10.1007/ s11663-009-9296-1.

[23] Zhang H., Fang Q., Deng S., Liu C. \& Ni H. (2019). Multiphase flow in a five-strand tundish using trumpet ladle shroud during steady-state casting and ladle change-over. Steel Research International, 90 (3). Doi: https://doi.org/10.1002/srin.201800497. 
[24] Morales-Higa K., Guthrie R.I.L., Isac M. \& Morales R.D. (2013). Ladle shroud as a flow control device for tundish operations. Metallurgical and Materials Transactions B, 44, 63-79. Doi: https:// doi.org/10.1007/s11663-012-9753-0.

[25] Solorio-Diaz G., Davila-Morales R., Barreto-Sandoval J.D.J., Vergara-Hernandez H.J., Ramos-Banderas A. \& Galvan S.R. (2013). Numerical modelling of dissipation phenomena in a new ladle shroud for fluidynamic control and its effect on inclusions removal in a slab tundish. Steel Research International, 85(5), 863-874. Doi: https://doi.org/10.1002/srin.201300224.

[26] ZhangJ., Yang S., Li J., YangW.,Wang Y.\&GuoX.(2015). Large eddy simulation on flow structure in a dissipative ladle shroud and a tundish. Iron and Steel Institute of Japan International, 55(8), 1684-1692. Doi: https://doi.org/10.2355/isijinternational. ISIJINT-2015-085.

[27] Solorio-Diaz G., Morales R.D., Palafox-Ramos J. \& Ramos-Banderas A. (2005). Modeling the effects of a swirling flow on temperature stratification of liquid steel and flotation of inclusions in a tundish. Iron and Steel Institute of Japan International, 45(8), 1129-1137. Doi: https://doi.org/10.2355/isijinternational. 45.1129.

[28] Solorio-Diaz G., Ramos-Banderas A., Barreto J. de J. \& Morales R.D. (2009). Modeling study of turbulent flow effect on inclusion removal in a tundish with swirling ladle shroud. Steel Research International, 80(3), 223-234. Doi: https://doi.org/10.1002/ srin.201090075.
[29] Solorio-Diaz G., Morales R.D., Palafax-Ramos J., Garcia-Demedices L. \& Ramos-Banderas A. (2004). Analysis of fluid flow turbulence in tundishes fed by a swirling ladle shroud. Iron and Steel Institute of Japan International, 44(6), 1024-1032. Doi: https://doi.org/10.2355/isijinternational.44.1024.

[30] Cwudziński A. (2010). Numerical simulation of liquid steel flow in wedge-type one-strand slab tundish with a subflux turbulence controller and an argon injection system. Steel Research International, 81(2), 123-131. Doi: https://doi.org/10.1002/ srin.200900060.

[31] Cwudziński A. (2014). Numerical and physical modeling of liquid steel active flow in tundish with subflux turbulence controller and dam. Steel Research International, 85(5), 902-917. Doi: https://doi.org/10.1002/srin.201300284.

[32] Cwudziński A. (2015). Numerical, Physical, and Industrial Studies of Liquid Steel Chemical Homogenization In One Strand Tundish with Subflux Controller. Steel Research International, 86(9), 972-983. Doi: https://doi.org/10.1002/srin. 201400207.

[33] Cwudziński A. (2014). Numerical, physical, and industrial experiments of liquid steel mixture in one strand slab tundish with flow control devices. Steel Research International, 85(4), 623-631. Doi: https://doi.org/10.1002/srin.201300079. 